\title{
THE URBAN STRUCTURE OF ROME BETWEEN HISTORY AND MODERN TIMES
}

\author{
Maria Grazia Ciancia ${ }^{\mathrm{a}}$, Daniele Calisi ${ }^{\mathrm{a}}$ \\ ${ }^{a}$ Dipartimento di Architettura, Università di Roma Tre, Largo Giovanni Battista Marzi 10, 00153 Roma, IT \\ mariagrazia.cianci@uniroma3.it, d.calisi@gmail.com
}

\section{Commission SG2}

\begin{abstract}
KEY WORDS: Cultural heritage, 3D Modeling, Web Gis, Digital Database, Iconography research, historical buildings, city
\end{abstract} structure, city history.

\begin{abstract}
:
The increasing use of computer technologies in projects involving the acquisition, documentation and communication of cultural heritage has led to a fast and ever more high demands of standards and methodologies in order to create best practices models. In the past years, in Europe it has been recorded a considerable interest in the digitization of Cultural Heritage and the creation of databases shared on the network (EUROPEANA, CARARE, 3D Icons), in the implementation of policies for the identification of shared global standards (EPOCH, MINERVA) and in the application of Web Gis (MAPPA, Mapping Gothic France). The research we project suits with this debate by proposing an innovative methodology for the investigation of the urban heritage. It should be able to document and represent the transformations that the city had during the time and the aim is to experiment a new methodology of knowledge and representation of the city.
\end{abstract}

\section{INTRODUCTION}

The rapid development of digital technologies has given rise, in the last few years, to a multiplicity of interpretations regarding the possible lines of research and application of numerical tools for the architecture and for its cataloguing and archiving.

The theoretical calculations regarding identify a series of points in common and lead to applications sometimes deeply different. The set of interpretative routes and application of digital technologies shows a complex panorama. In an attempt to outline an interim framework of research in act is necessary to examine works of architecture that need an in-depth study, a control of transformations and, most importantly of all, the organization of heterogeneous data.

The scope of the architecture is oriented to understand the new territories of the digital space: unstable systems, generic city, passage zones; spatial modifications but especially mental changes.

Through the digital, architecture discovers a possible explosion of its areas of interest within a large space, diffuse, inhabited by a community of millions of people, a space that is no longer possible to consider as a place of an abstract experimentation, separate from the physical environment, but is necessary to consider it as a meeting place, of verification and especially of an exchange.

At this time of change is necessary, therefore, a reflection on the ideas and issues that describe the current condition, and a critical discourse on the role and possible competences of the architecture in the face of the changes produced by the digital revolution.

The contemporary architecture comes into contact with that historical, dialoging, comparing, generating reports sometimes practical, sometimes only virtual.

The multitude of data that one has to manage each and every time one operates on a complex territory from the historical point of view, needs a managing by computers that, stores and organizes them for their fast management (research, deletion, insertion).

The same search engines of Internet access through middleware to databases (multimedia type) to find the information requested by users.

It is necessary that the reports is able to establish productive connections in any direction, away from singular hierarchies, monolithic and static toward those more identifiable with a dynamic network of interconnected elements.

Relations are always changing and are determined by the boundary conditions, thus in our research project the relations between the constituent parts will vary depending on the interaction between information technology, users of data and the data themselves.

\section{THE ERA OF DIGITIZATION}

In modern times, the technology has led us to believe that everything is easily accessible, determinable, and analyzable.

However this is a false common sense: being able to purchase and catalog millions of songs certainly were not led us to appreciate more the music; being able to create an everincreasing amount of digital drawings, does not led us to appreciate more the drawing; being able to have a whole library of e-books on our tablet, did not make us appreciate more the reading.

One could continue with examples or metaphors, even thoughtlessness, only to clarify a concept that we believe important for the purposes of this paper: the avantgarde, the technology, and innovation have nothing to do with the actual usability and enjoyment of an asset, especially if it is historical and culturally significant.

The historical centers of Italy, Europe and the world have a unique importance and significance, as well as the case of the proposed Rione Monti. 
Obviously, the more ancient is the historic center, the greater the complexity of reading of its personalities and its time-series. In this sense, Rome is clearly an emblematic and unique case. Unfortunately, the reading of certain urban fabrics, cannot be simplistic or simplified, but must necessarily be detailed and extensive.

The overall vision that modern systems WEB GIS for cataloguing and archiving is a global vision, not taking care of that "local".

The Geo Systems exploit in most cases satellite images obtained from terrestrial remote sensing, aerial photographs and topographic data stored in a GIS platform.

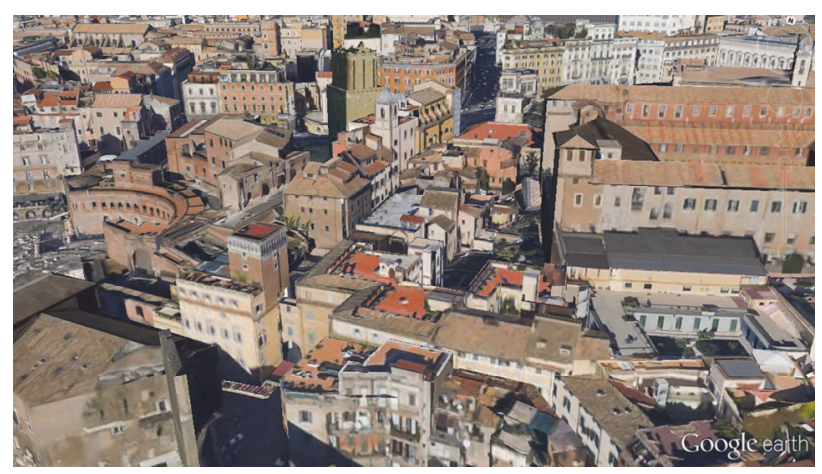

Figure 1. View of the area of the ascent of the Grillo, as it is displayed by Google Earth.

This allows users to be able to navigate on common platforms, or specific, three-dimensional models simple mapped through satellite photos.

This system was and still is today innovative, but we would like to put attention to a fundamental question: these platforms continue to give information and basic notions of the environment.

The increasing use of computer technologies in projects involving the acquisition, documentation and communication of cultural heritage has led to a rapid and ever more pressing demand for standards, and best practices in order to create the cases of best practices.

In these years in Europe was recorded a lot of interest in the digitization of the Cultural Heritage and the creation of databases shared on the network (EUROPEANA, CARARE, 3D Icons), for the implementation of policies for the identification of shared global standards (EPOCH, MINERVA) and for the implementation of the Web Gis (MAP, Mapping Gothic France).

The problems to be dealt with in the district of the Suburra makes the area particularly interesting and rich of ideas for the development of a methodology of study, articulated on various levels of knowledge.

One will be able to experience, verify and validate the methodologies previously applied in order to receive and give a innovative response to the instances required by the application of ICT in the documentation of Cultural Heritage (Horizon 2020 - ICT for digital content and creativity).

In particular, starting from the inspiration from modern Web Gis, it is considered the best methodology to use in order to create a system with more detailed, scientific, punctual and analytic informations of the urban space.

This of course can be created only if to develop such information are not machines or satellites, but if the specific and rational research is entrusted to the hand of man.

\section{HISTORICAL-ANALYTICAL} RECONSTRUCTION METHODOLOGY

In order to structure the studies and have a precise scheme for the development of them we have defined some fundamental steps. Research has touched some of them and we hope to develop it more, in an attempt to keep faith to the final stages:

- Collection of historical documents in the archives (bibliographic sources, photographs, historical or recent cartography, engravings, drawings, documental title blocks).

- Cataloging, digitization, organization of the material collected in a database that maintains information on metadata (source and archives).

- Collection of metric data: identification of the more suitable methodologies of urban and architectural survey to document the urban scene (topographic survey for the georeferencing data, laser scanning, photo modeling).

- 3D reconstruction of the present urban scene where to place and to georeference virtual reconstructions produced from the graphic and analytical elaborations of the historical and archival material.

- Virtual Reconstruction of the urban and architectural consistency of the lost urban fabric and its timeline.

- Relationship between database and virtual model to build a system of geolocalized information on different scales of representation (urban, building, detail). The created 3D multilayer model will be a powerful WEB GIS tool that will allow the creation of diachronic and synchronic themes of the area in order to display its structure according to different periods and to different transformations.

On the basis of what has been said, then it is clear that the first steps in this scheme are those that are missing from modern Gis or ITC systems: give a characterization of the urban space that is not limited to the current form, but that studies the layerings also through the many archival sources.

The collection of historical and archive documentation is essential for understanding the development of spaces and urban fabrics: bibliographic sources, photographs, historical and recent cartography, engravings, drawings, documentary cartouches, are all of them useful to trace the evolution and the transformations following in the course of history.

The database has been designed so that it can be inserted in the future in a web GIS, by sharing on line, with the scientific community and not, information that are often hardly accessible and usable.

\section{HISTORIC TO CONTEMPORARY: THE TRANSFORMATIONS OF RIONE MONTI}

The archive sources were essential to the realization of a generic three-dimensional model representing the district from 1824 to 1871 date of the third update of the First Gregorian Cadastre. All the documentation provides - as with other city of the papal State - a true picture, extremely thorough of urban areas, of the functional aspects and of the economic life of Rome before the Unit. Monuments and gardens are often represented with great effectiveness pictorial.

The $3 \mathrm{D}$ created could be comparable to the one managed by, for example, Google Earth, but without the application of photographic texture: it is made of pure volumes representative of buildings such as described in the "brogliardi" connected to cadastral sheets.

It could also be implemented the time-series reconstruction of individual buildings, with all the problems related but it would have been obviously a reconstruction too heavy in terms of 
bytes. We preferred instead to focus on some emblematic areas of the transformations undergone by the Rione, and of which was made a three-dimensional model both of the 1871 with the related building types and both of the current state.
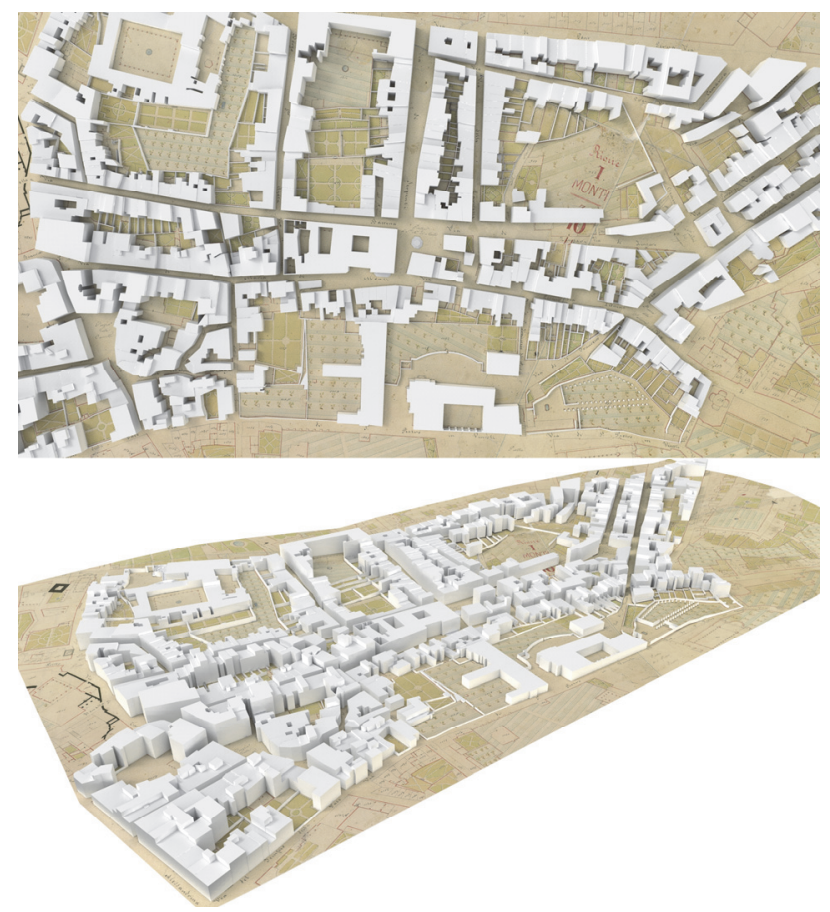

Figure 2. Three-dimensional model simplified of Rione Monti based on the Gregorian Cadastre and the respective "brogliardi" that provide the volumetric data.

In order to understand the development of urban space, and its buildings, it must first focus on the study of the current state, which gives us plenty of information clearly hidden in facades of the historical buildings: earthen mounds, changes of front, opening and closing of windows, merging of more neighbouring buildings.

Even before one try and dig up the historical transformations in the archives and through licenses and historic permits, one must learn to read the historical buildings that are open book for an eye trained and educated.

The first phase of the survey, conducted with the appropriate technologies and relevant to case-studies, is the first step to proceed from a general vision to a local one: watch, observe, draw, measure are the actions that enable us to study and understand a building.

Of course, as with any survay, it must be done first a discretization: decide what detect, how to detect it and with what instruments, also in function of the scale of representation. Obvious that from a detail in real scale 1:1 to the parallelepipeds texturized of Web Gis, there is an entire intermediate casuistry, in order to better represent the architecture and the city. In this specific case, it was a kind of representation of urban type, for which the detail chosen was that of a scale 1:100 maximum.

The detection phase was also quite complex because the planimetric base from cadastre, which derives precisely from satellite systems, had considerable differences with measurements verified in situ.

The design of the facades in the current state has followed a similar process: in some cases occurred the existing basis, by comparing the measures taken with the reliefs from the archives, in other cases, it is proceeded to the direct detection and by photo correction.

The latter was the method most used because, for the purposes of urban analysis, the detail to reach could not be what a laser scanner can give (or a photomodeling).

So that the inspection, the measurement of the facades in their principal dimensions, the photo correction with specific programs and the redrawing of the same, having also present the casuistry of the roman historical moldings, have led to a result that is more than satisfactory.
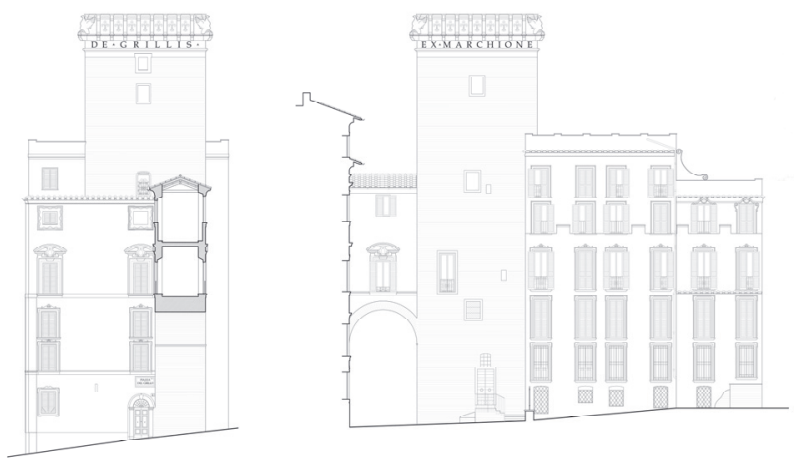

Figure 3. Survey of Palazzo del Grillo. Section overlooking via Biberatica with details in the scale 1:100. The basic twodimensional has been verified, and discretized in order to continue the modeling of the architectural elements.

This two-dimensional base was already an excellent starting point for the three-dimensional modeling of the existing.

However, even in the act of modeling with specific software, we have to be very careful to the constructional elements, the geometries type of classic architectures, the decorative elements and the way to simplifying them the better, the ground attacks on a varied orography.

The historic architecture has such a complexity as to make the step of three-dimensional modeling extremely complex.

If the geometries are not exact, it is unlikely that one are unable to model the forms such as cornices, gable, shelves, molded cornice window, doors, columns and balconies with "balaustrini".

Moreover, with respect to the two-dimensional, in 3D must be made a further simplification, not so much for those moldings that derive from sections, but for those ornamental elements, often organic, which burdens too much the model and they would not be appreciable in the urban scale.

It is obvious that such a three-dimensional model has a quantity of information considerably higher than Web Gis systems, whose textures are often of low resolution or incorrect.

At the conclusion of this phase one will have the threedimensional reconstruction of the urban scene current georeferenced, as the basis for the articulation of the WEB GIS and virtual reconstruction.

Certainly the current Web Gis are a great base to view the urban space.

It remains clear that there are many differences between a model made of simple volumes, deep texturizeted sometimes without any criterion because deliberately (and, I think, rightly so) generalized and simplified in the forms, and a template created from the study of the existing architecture with all its peculiarities. 

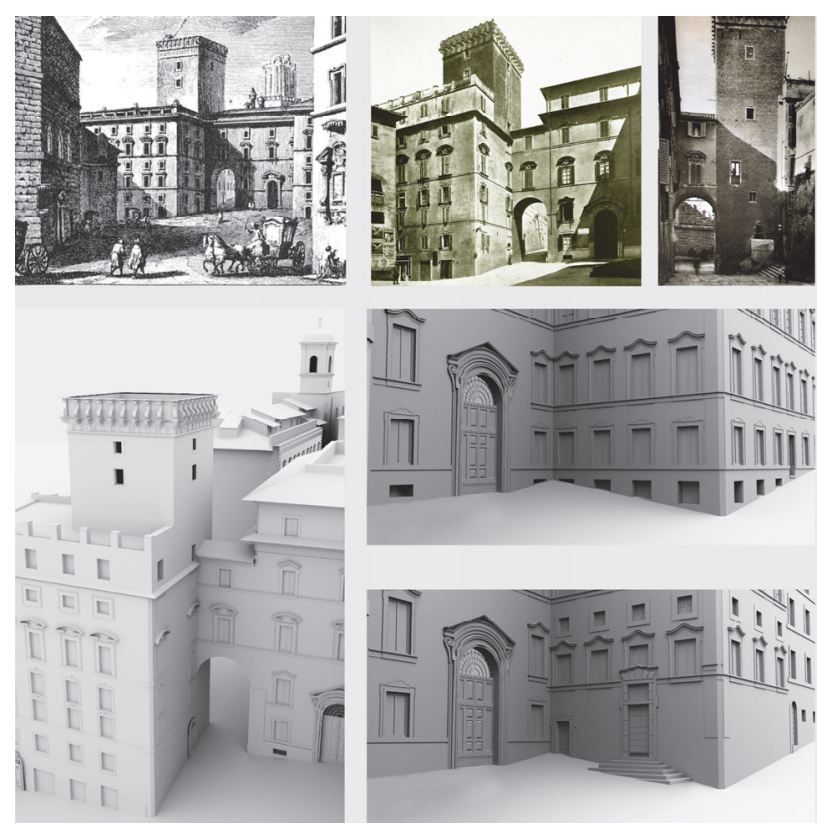

Figure 4. View of the Church and the Monastery of S. Maria Annunziata (Vasi_1761). Views of the Tower and Grillo the Palace (1930). 3D modeling reconstruction of the current state, compared with the reconstruction from historical sources.

\section{VIRTUAL RECONSTRUCTION HYPOTHESIS}

The last step of the process (but there are different if you want to secure the urban fabric in various historical phases) was to recreate the urban space before the demolition of the Rione Monti, according to a common sense of the time (think also to demolition or parisian viennese) in view of the embodiment of via Cavour.

The hypothesis of reconstruction of buildings and existing contexts was performed on the basis of the interpretation and processing of the documentation found related to the urban scene today.
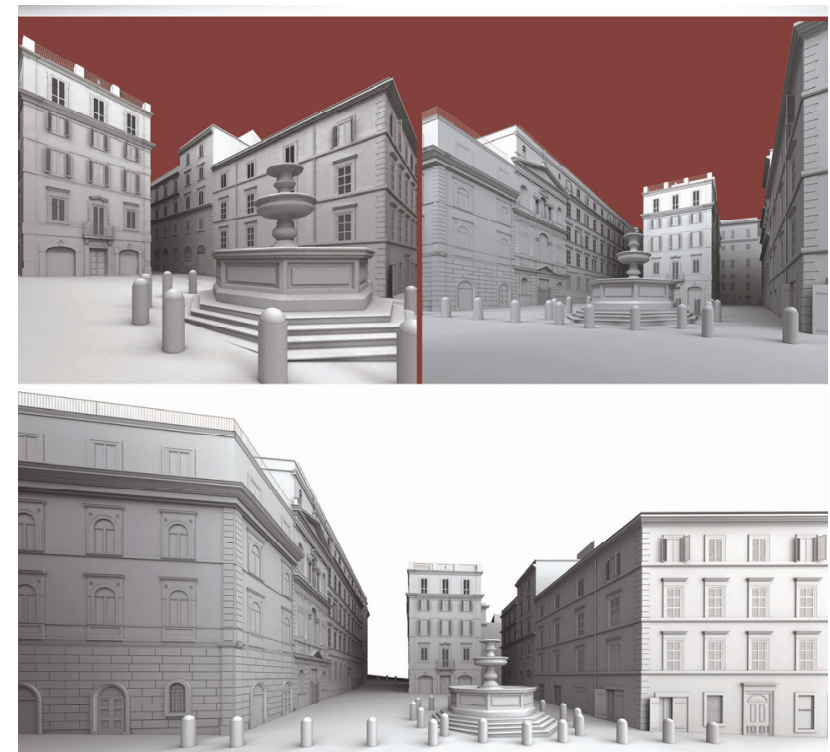

Figure 5. Some views of Piazza Madonna dei Monti: 3D model of the current state survay.

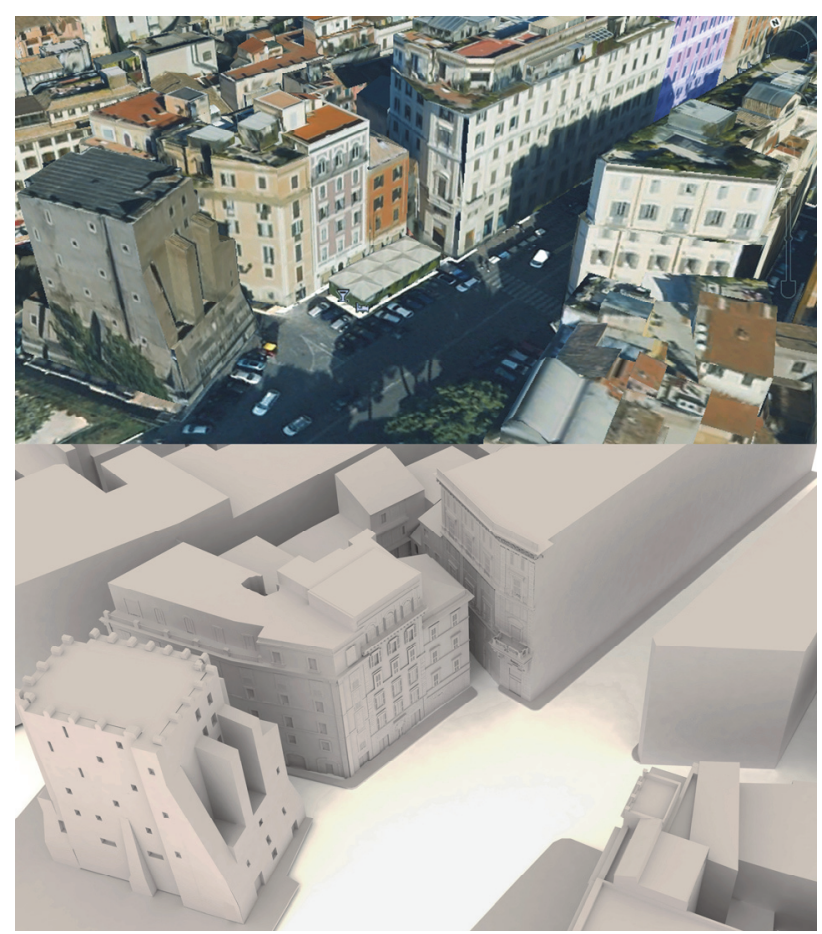

Figure 6. Comparation of the Google Earth view and the 3D model from survay of Largo Corrado Ricci, that took place of Piazza delle Carrette after the demolitions.

The hypothesis of reconstruction of buildings and existing contexts was performed on the basis of the interpretation and processing of the documentation found related to the urban scene today.

In particular, it must be pointed out, that the hypothesis of reconstruction has followed three basic guidelines depending on the type and the amount of archive documents retrieved.

First of all a common base that has allowed us to understand the urban structure of the Rione: the Gregorian cadastre in which are marked the living particles, and their respective "brogliardi", booklets containing basic information on the number of floors and the properties of each individual unit.

Then the documentation in the archives, formed by the various licenses granted by the City Hall on any earthen mounds or annexation of facades, reliefs of the units to be demolished in relation to new projects of the new road artery of Via Cavour, documentation of expropriation, the iconography of Rome, the antique photographs useful to understand the urban space and the orography.

In some cases, one you can find descriptions of the fronts of the interior, the courts or the finishes of the buildings, which are also very useful for historical reconstruction.

All this documentation is essential and necessary for an accurate reconstruction as realest as possible. In fact is not always possible to find archive documents on each building, therefore, the interaction of all the archival components is useful to obtain a realistic hypothesis or at least consistent.

In relation to the principles enshrined in the charter of London (Computer-based visualization of Cultural Heritage) and the Charter of Seville (Virtual Archeaeology), in the reconstruction phase it is necessary to identify and separate the different degrees of trust of the reconstruction.

In accordance with the principle of "authenticity" the reconstructions will be organized by layer defined on the quality of the initial data (full data, partial data, incomplete data ) . 
In any case all the information until it structured on the database allow the processing of the hypothesis of the reconstruction of the urban evolution of the framework studied on different levels of reading (multilayer).

We can distinguish three different guidelines for the hypotheses reconstructive.

The first one, and easier, and that more realistically valid because the solutions adopted are exactly identical to archive documents: for in such cases there are, in fact all the required documents, including drawings ante and post operam, any licenses, photographs, descriptions.

Of course, the presences of this considerable documentation leaves no margin of error on the assumption of threedimensional model.

The second theory has an archival base less impressive and sometimes to have gaps in the reliefs or in projects submitted, and in some cases, for example, were present or only the floor plans, or only the facades, or a sequence of plants. But just with these we already provides plenty of information for the volume reconstruction, and often the descriptions of the buildings have provided the gaps in the drawings, for the presence or not of frames, urbanist or ornaments, the latter were reconstructed simplified, not having further detailed drawings.

Finally, the third hypothesis is the less realistic because the documentation was virtually non-existent, except maybe a few historic photo, In this case it was for building types primarily based on the plan of the Gregorian cadastre.

The numerous studies on the evolution of the domus romana and the subsequent home italica, have allowed to assume the housing types on the basis of the distance of load-bearing walls, the number of the plans and the shape of the roofs was consequent to the choice of the type building, while for the fundamental ornaments there is limited to simple frames, exploiting the rich case study of housing types like in the area of study.

In three-dimensional model of the historical reconstruction the three different ways of recovery are clearly evident through the use of different colors for the buildings.

This digital archiving system is the desirable future for a method of cataloguing of assets, private collections in the arts and documentation archive.

Today this elaborate process is limited only to the wealth of books, pictorial, parietal and archive (although the acquisition is a very slow process).

What is lacking is a digitalized collection of the architectural heritage, described at multiple levels of representation.

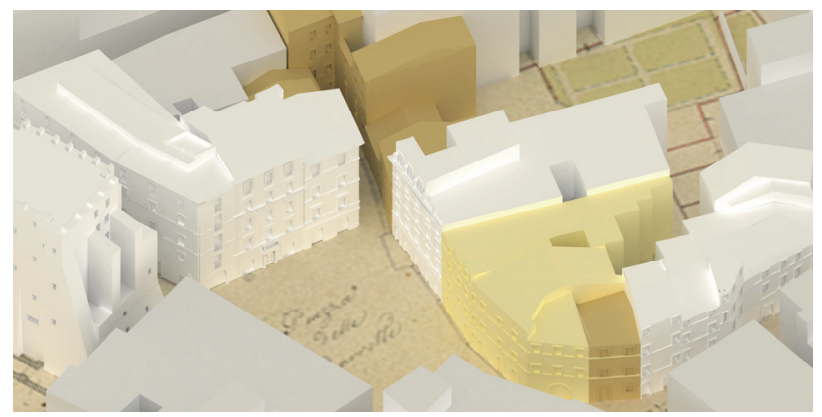

Figure 7. Riconstruction of Piazza delle Carrette, with different colors of buildings explaining the three rebuilding hypothesis.

\section{CONCLUSION}

Through a critical eye to the urban context and identifying the individual buildings in their complexity, it demonstrates the need to establish a system in order to communicate their different levels of interaction with the various architectural elements that should be preserved and accessible in the same way as a work of art.

The cataloguing at different levels affects the different scales of representation of the city and the interactive fruition for users who are interested in historical research or cognitive.

The hierarchy of levels of storage of the city should be experienced even at a level more superficial, such as, for example, from a simple user, almost oblivious to the knowledge offered by the storage system and its language interactive, for example the case of a tourist or a citizen that is eager to deepen their knowledge of a building, or a district also simultaneously with its historical stratification and architectural.

The survey concerning the historical formation process that has led to the current structure of the Rione Monti, and in particular, the portion of the original territory that can be identified using the ancient toponym Suburra, is an emblematic and exemplar story which, at the level of principles and method of study, can be generalized and applied in other areas of the city that, as this one, have time-series and still preserving clearly legible and interpretable traces.

The knowledge of the chosen urban context requires a necessary and in-depth historical research that examines the bibliographical references, the historical documents, the archive materials already known and further develops the investigating of the historical sources to increase and complete the study.

The understanding of the urban structure is based on the theories set out in the years ' 60 of the last century by Saverio Muratori and his school, then increased and refined by the studies conducted by Gianfranco Caniggia. It is, therefore, fundamental to analyze the geomorphology of the soil, to retrace the main steps in the formation of the urban fabric and to put into connection the development of the routes with the architectural transformations and with the evolution of the building types.

The stratification that succeeded in three millennia of urban history should be then interpreted is recognized in all its different components: for this purpose it is a useful support the reading of the historic iconography produced, which, from different points of view and with various levels of graphical definition, represents the city in its evolution.

The area that has been examined is delimited by via Panisperna, via Cavour and via dei Fori Imperiali: the urban fabric included within these limits has maintained characters of uniformity and architectural homogeneity such as to make it distinguishable and recognizable as a fragment of an historical context.

The configuration and the position of this region have caused its participation in the formation of the town since its early stages, and a urban development contextual to the urban growth: the cards describing the archaeological findings provide with documentary evidence the existence of the most ancient tracks, the Argiletum and the vicus Patricius, and confirm the use of them during the Republican and Imperial Rome.

During the Middle Ages, this area, as many other parts of the town, suffered a considerable demographic decline associated with a gradual transformation of the physiognomy of the territory where, however, the same originating paths remained in use with the function of processional routes documented for the VIII and the XII century.

And, although this demonstrates a never ceased interest on this area, it's only from the last decades of the '500 that was accomplished a planned work of reclamation which was followed by the urban recovery of the whole area.

The first intervention that sign this renewed interest in the Suburra is the tracing of the straight Via Panisperna that, 
planned by Pope Sixtus V, sighted the apse of Santa Maria Maggiore; differently, the other roads created subsequently, followed the orography of the soil and layedin parallel to the ancient paths and were characterized by building types that simultaneous with the development of the tissue were also renovated.

This process is efficaciously attested by the renaissance iconography and in the lapse of a century it is possible to attend the gradual and intense transformation that gives life to a complex and articulated building fabric that then reaches its more complete definition at the end of baroque restructuring, when in 1748 is represented by Nolli.

Comparing the views with the subsequent plants, before the Nolli one and then the Catasto Urbano Pio Gregoriano, it seems possible to say that beyond the renaissance and baroque works, the analyzed area has not been subjected to particular urban transformations, probably only punctual intervention of building transformations and obstruction of free areas, growth in height of the buildings and aggregation of parcels, local arrangements to which it's possible to assist by observing the many documents preserved in the archives.

Regarding to this the research has carried out some thematic indepth analysis which led to the re-discovery of the places during specific historical periods:

- The baroque aspect of piazza Madonna dei Monti and of piazza degli Zingari,

- The relation between piazza del Grillo and the archaeological context, acquire meaning through the $3 \mathrm{~d}$ modeling that by ordering in a whole graphic the multiplicity of documentary information allows to reconstruct the original places, those recognized as the most significant, the ones still corresponding to the physiognomy organically more completed in this portion of the town.

- The transformations followed to the unity of Italy, the many demolitions and reconstructions, and in particular, the construction of via Cavour and the opening of via dei Fori Imperiali, have instead torn the pre-existing building fabric.

This is shown through the remodeling graphics for the opening of via dei Serpenti, and the subsequent demolition of the building environment overlooking the church of the Madonna dei Monti of which it is considered appropriate to preserve the memory.

The survey was then focused on the study of the places most compromised by these interventions, environments now disappeared and otherwise destined to be forgotten: the piazza della Suburra and piazza delle Carrette, were vital places and represented social and urban centrality with the function of connection between the historic built whose configuration is useful to find through the drawing to document the complexity of an area now reduced to a fragment of itself.

The method brought forward and the results achieved represent a favorable instrument of knowledge and documentation, which inaugurates the opportunity to make the discipline more accessible and widely usable.

It is useful for the conservation and valorisation of cultural heritage both in restoration initiatives, which must consider the history of the single building but also its surrounding context, and in the contemporary planning interventions that also has to be integrated with the cultural heritage.

The visual documentation, the dissemination of studies and their dissemination to the wider public have effects on economic process both from the point of view of cultural tourism and sustainable management of the territory (superintendents, municipal offices, local authorities, public and private archives)
The research will also functional to the valorisation of urban spaces suspects and will be an important resource in any future interventions of restoration and conservation, the social impact of the research has implications for citizens who will be the first to recover the historical memory of the urban spaces lost, by scanning the transformations through the virtual simulation of a heritage now forgotten, the benefit from the information quickly through the network is a prerogative that affects mainly young people that with this kind of applications can be closer to the culture by taking an in a spontaneous way to the rediscovery of their city. This phenomenon will lead a relapse socio-cultural significance with educational implications.

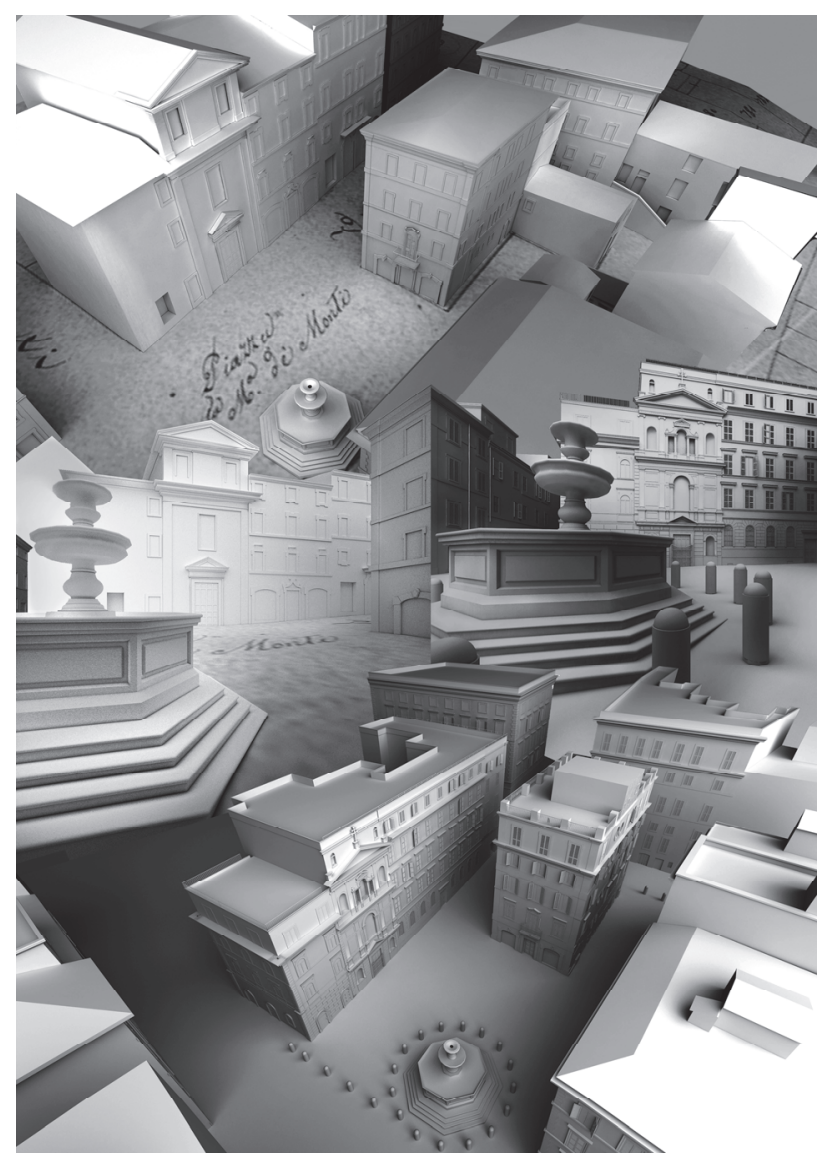

Figure 8. Some views of Piazza Madonna dei Monti, made from the three-dimensional model as it is made after the survay of the current state, and comparation with the 3D model of historical phase.

\section{References from Books:}

Arnheim R., 1965. Arte e percezione visiva. Milano.

De Simone M., 1990. Disegno, rilievo, progetto. Il disegno delle idee, il progetto delle cose. Roma.

Muratori S., Bollati R., Bollati S., Marinucci G., 1963. Studi per una operante storia urbana di Roma. Roma, Centro Studi di Storia Urbanistica.

Caniggia G., Maffei G.L., 1979. Lettura dell'edilizia di base. Venezia.

Corsini M.G., 1998. Tipi e tessuti del centro storico di Roma. Lettura del costruito per il progetto. Edizioni Kappa, Roma. Guide Rionali di Roma, 1984. Rione I Monti (4 parti). Fratelli Palombi editori. Roma. 